\title{
Alur Pendaftaran Calon Mahasiswa Baru Politeknik Sekayu Berbasis Multimedia
}

\author{
Zaid Romegar Mair \&Yuni Kartika \\ Teknik Informatika, Politeknik Sekayu \\ Email : romegardm@gmail.com
}

\begin{abstract}
Multimedia is one form of information technology, namely information technology that combines images, writing, text, sound, video, animation into an information system that is useful in making decisions for its users. This media displays information about the registration flow of prospective new students in a clear and concise manner. The method used is the MDLC (Multimedia Development Life Cycle) method as software development. For an explanation of each registration flow information using audio, in addition to making this media more interesting, characters or animations are displayed Keywords: registration flow, Multimedia, MDLC.
\end{abstract}

\section{Pendahuluan}

Untuk penerapan multimedia dapatdikembangkan menjadi media promosi yang lebih menarik dan interaktif. Multimedia merupakan salah satu bentuk dari teknologi informasi, yaitu teknologi informasi yang menggabungkan gambar, tulisan, teks, suara, video, animasi menjadi system informasi yang berguna dalam pengambilan keputusan bagi penggunanya.

Berdasarkan permasalahan di atas, Penulistertarik untuk mengajukan judul Tugas Akhir "Alur Pendaftaran Calon Mahasiswa Baru Politeknik Sekayu Berbasis Multimedia ". Dengan harapan media ini sebagai media pengenalan masyarakat luar atau umum tentang alur pendaftaran calon mahasiswa baru yang ada pada Politeknik Sekayu.

Berdasarkan latar belakang diatas dapatdibuat rumusan masalah, yaitu bagaimana cara membuat sebuah alur pendaftaran calon mahasiswa baru politeknik sekayu berbasis multimedia sebagaimedia penyampaian informasi yang dapat menjadi solusi bagi calon mahasiswa baru yang inginmendaftar di Politeknik Sekayu.

\section{Tinjauan Literatur}

\subsection{Sejarah Singkat}

Politeknik Sekayu resmi berdiri berdasarkan Surat Keputusan Menteri Pendidikan Nasional Republik Indonesia Nomor : 221/D/O/2007 Tanggal 29 November 2007. Politeknik Sekayu merupakan Politeknik milik Pemerintah Kabupaten Musi Banyuasin yang penyelenggaranya dilaksanakan oleh YayasanMuba Sejahtera di Sekayu.

Didalamnya upaya peningkatan kualitas pendidikan dan pengembangan Politeknik Sekayu kedepan, upaya yang telah dilakukan diantaranya keikutsertaan Politeknik Sekayu dalam Program Hibah Pendirian Politeknik Batch 2 yang diselenggarakan oleh DIKTI. Program hibah ini dalam upaya membangun dan mendukung penyelenggaraan 3 (tiga) program Studi yaitu :

- Program Studi Akuntansi

- Program Studi Teknik Informatika 
- Program Studi Teknik Pendingin dan Tata Udara

Yang penyelenggaraannya dimulai pada Tahun Akademik 2008/2009.

\subsection{Pengertian Multimedia}

Menurut HR Widada (2011, p.7) Multimedia merupakan kumpulan berbagai sarana yang dimiliki atau dibuat oleh komputer, meliputi objek teks atau angka, gambar, animasi, video dan audio. Dengan multimedia kita dapat melakukanbanyak hal, seperti mendengarkan musik, memutar video, membuat objek teks dan bangunan, mengelola gambar atau foto, mengelola video, membuat animasiserta pembuatan presentasi atau media pembelajaran.

Menurut Juhaeri (2013, p.1) Multimedia secara umum merupakan kombinasi tiga elemen yaitu suara, gambar dan teks atau gabungan video, audio, grafik dan teks dalam suatu produksi bertingkat berbasis komputer yang dapat dialami secara interaktif.

Berdasarkan pengertian di atas dapatdisimpulkan bahwa multimedia adalah gabungan dari dua atau lebih unsur teks, grafik, suara, gambar, video dan animasi yang disajikan kepada pengguna untuk menerima informasi secara lebih mudah.

\subsection{Pengertian Informasi}

Menurut Gordon B. Davis (dalam Al- bahra bin ladjamudin 2013:8) “ informasi adalah data yang telah diolah menjadi sebuah bentuk yang berguna dan nyata atau berupa nilai yang dapatdipahami dalam keputusan sekarang maupun yang akan datang".

Menurut Sutarman (2012:2), informasi adalah sekumpulan fakta (data) yang diorganisasikan dengan cara tertentu sehingga mereka mempunyai arti bagi si penerima.

Berdasarkan pengertian diatas dapat disimpulkan bahwa informasi adalah data yang sudah jadi siap digunakan untuk pengguna.

\subsection{Adobe After Effects}

Menurut Edi dan Sudaryatno (2014 : 3) "menerangkan bahwa Software yang digunakan untuk film dan pos produksi pada video. After Effects adalah software yang sangat profesional untuk kebutuhan motion graphic design, denganperpaduan dari bermacam macam software designyang telah ada".

Adobe After Effects adalah salah satu softewarecompositingyang populer dan telah digunakan secara luas dalam pembuatan video, multimedia, film dan web. After effects terutama dipakai dalam penambahan efek khusus seperti efek petir, hujan, salju, ledakan bom, dan efek khusus lainnya. After effects telah membantu para praktisi perfilman Hollyworddalam menghasilkanfilm-film dengan efek khusus yang spektakuler. Adanya kesamaan interface antara After effect dengan keluarga adobeyang lain seperti Photoshop memberi kemudahan dan kenyamanan dalam pemakaiannya. Integrasi after effect bersama dengan photoshop, illustrator, dan premier akan menghasilkan karya yang sebelumnya sulit dibayangkan untuk diwujudkan.

\subsubsection{Software Pembuatan Aplikasi}

Aplikasi ini dibuat dengan beberpasoftware pendukung dalam perancangan maupun implementasinya. Software yang digunakan dalam pembuatan aplikasi ini antara lain sebagai berikut : 
1) Adobe After Efects

Adobe After Effects adalah salah satu softewarecompositingyang populer dan telah digunakan secara luas dalam pembuatan video, multimedia, film dan web. After effects terutama dipakai dalam penambahan efek khusus seperti efek petir, hujan, salju, ledakan bom, dan efek khusus lainnya. After effects telah membantu para praktisi perfilman Hollyworddalam menghasilkan film-film dengan efek khusus yang spektakuler.

\section{2) Adobe Photoshop CS3}

Adobe Photoshop adalah software yang digunakan untuk memodifikasi gambar atau foto secara profesional baik meliputi modifikasi obyek yang sederhana maupun yang sulit sekalipun. Photoshop merupakan salah satu software yang berguna untuk mengolah gambar berbasis bitmap, yang mempunyai tool dan efek yang lengkap sehingga dapat menghasilkan gambar atau foto yang berkualitas tinggi. Kelengkapan fituryang ada di dalam photoshop inilah yang akhirnya membuat software ini banyak digunakan oleh desainer grafis profesional. Dan mungkin juga sampai saat ini masih belum ada software desain grafis lain yang bisa menyami kelengkapan fitur dalam Photoshop.

\section{3) Audio Editor Master}

Audio Editor Master adalah audio digital editor yang memungkinkan anda untuk melakukan berbagai operasi dengan file audio seperti cut, copy dan fitur paste (dengan fungsi undo tak terbatas), mix lagu atau menerapkan efek rekaman. Program ini tidak hanya dapat merekam dan memutar suara tetapi juga mengimpor dan mengekspor berbagai macam file didukung audio (WAV, AIFF, MP3 dan OGG, dll).

\subsection{MDLC (Multimedia Development Life Cycle)}

Metode perancangan system yang digunakan dalam membuat aplikasi ini adalah metode sistem MDLC (Multimedia DevelopmentLife Cycle) versi Sutopo A.H, (2012). Tahapantahapan yang terdapat dalam metode MDLC (Multimedia Development Life Cycle) yaitu: concept, design, material collecting,assembly, testing, distribution (Antoni, Fikari \& Akbar, 2018; Antoni \& Akbar, 2019; Antoni, Jie \& Abareshi, 2020; Antoni, Herdiansyah, Akbar \& Sumitro, 2021).

\section{Metode Penelitian}

\subsection{Spesifikasi Kebutuhan PerangkatKeras (Hardware)}

Spesifikasi minimal kebutuhan pada laptop untuk menginstal dan menjalankan adobe dalampembuatan alur pendaftaran calon mahasiswa baru ini yaitu sebagai berikut:

1) Memory RAM $2 \mathrm{~Gb}$

2) Processor Intel i3

3) VGA Card $256 \mathrm{Mb}$

4) Hardisk $500 \mathrm{~GB}$

5) Dan pendukung perangkat keraslainnya 
Spesifikasi kebutuhan untuk menjalankan video alur pendaftaran calon mahasiswa baru ini yaitu sebagai berikut :

a) Memory RAM $1 \mathrm{~Gb}$

b) Processor Intel i3

c) Hardisk $500 \mathrm{~GB}$

\subsection{Spesifikasi Kebutuhan PerangkatLunak (Software)}

Adapun perangkat lunak yang digunakan penulis dalam Membangun video profil sekolah ini yaitu sebagai berikut :

a) Microsoft Windows 10 Profesional 64 bit,

sebagai sistem operasi

b) StarUML 5.0.2.1570, digunakan untukperancangan diagram UML

c) Microsoft Visio 2010, digunakan untukperancangan interface

d) Adobe After Effect, digunakan untukmembuat animasi dan editor video

e) Adobe Photoshop CS3, digunakan untukmengedit gambar

\subsection{Perancangan Antarmuka}

Perancangan antarmuka Alur Pendaftaran Calon Mahasiswa Baru Politeknik Sekayu Berbasis Multimedia ini dimana informasi alur pendaftaran akan ditampilkan secara keseluruhan dalam video. Pada perancangan ini terdapat beberapa bagian yang akan ditampilankan dalam video. Rancangan antarmuka nya terdiri dari :

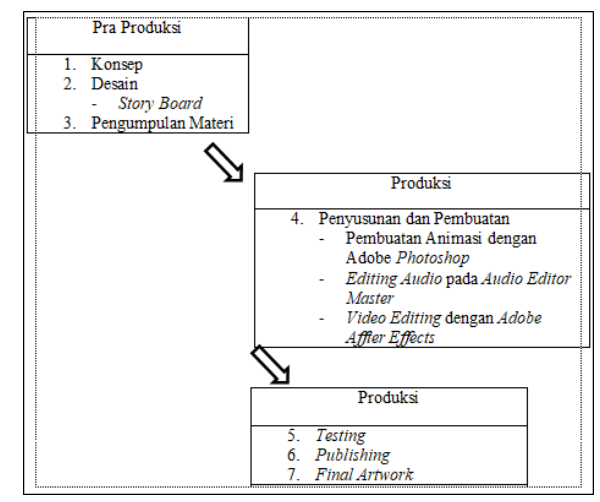

3.4 Rancangan StoryBoard

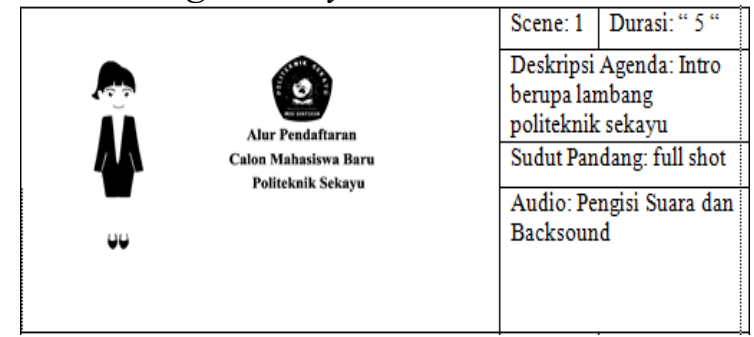




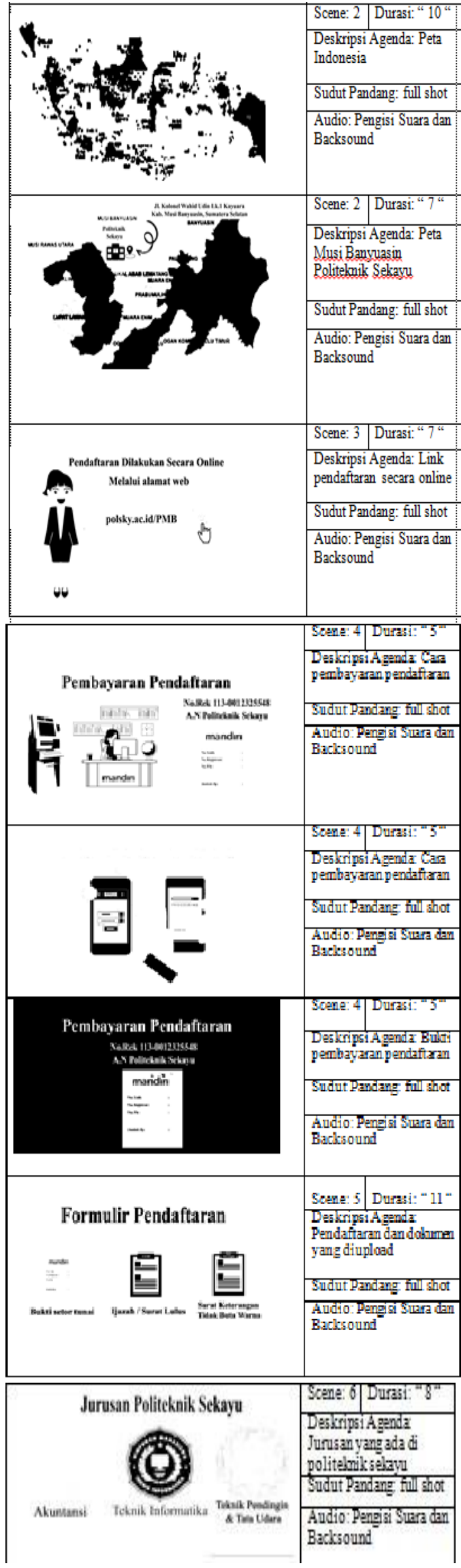

Published by: 


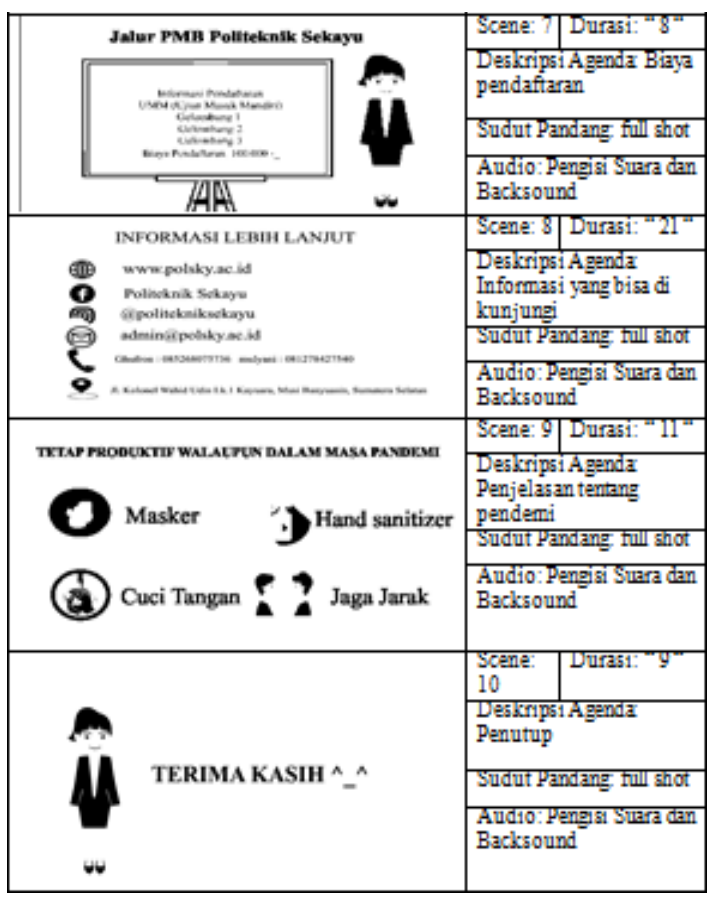

\section{Hasil dan Pembahasan}

\subsection{Hasil}

Laporan tugas akhir yang dibuat adalahmedia informasi Vidio alur pendaftaran calon mahasiswa baru Politeknik Sekayu. Media informasi ini terdiri dari beberapa tampilan yaitu terdapat tampilan intro dan tampilan isi yang berisi infomasi mengenai alu pendaftaran. Ketika video dimulai langsung ke halaman intro, di halaman intro tersebut berisi animasi intro dan logo Politeknik Sekayu. Selanjutnya akan munculkarakter yang akan memberikan penjelasan alur pendaftaran dalam bentuk audio.

\subsection{Tampilan Intro}

Halaman intro adalah halaman yang menampilkan animasi karakter dan animasi tulisan.

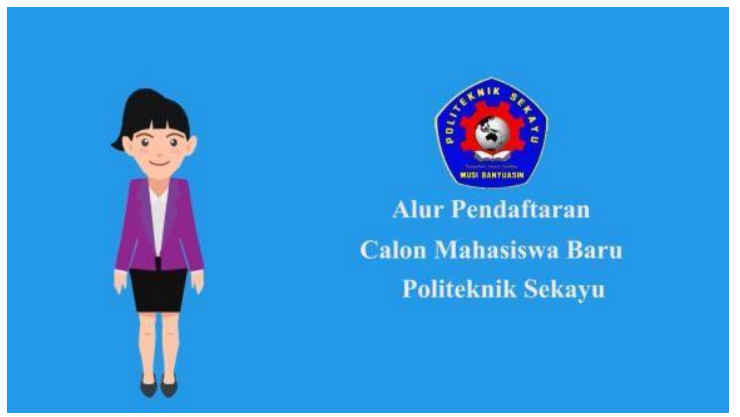




\subsection{Tampilan Animasi Lokasi Politeknik}
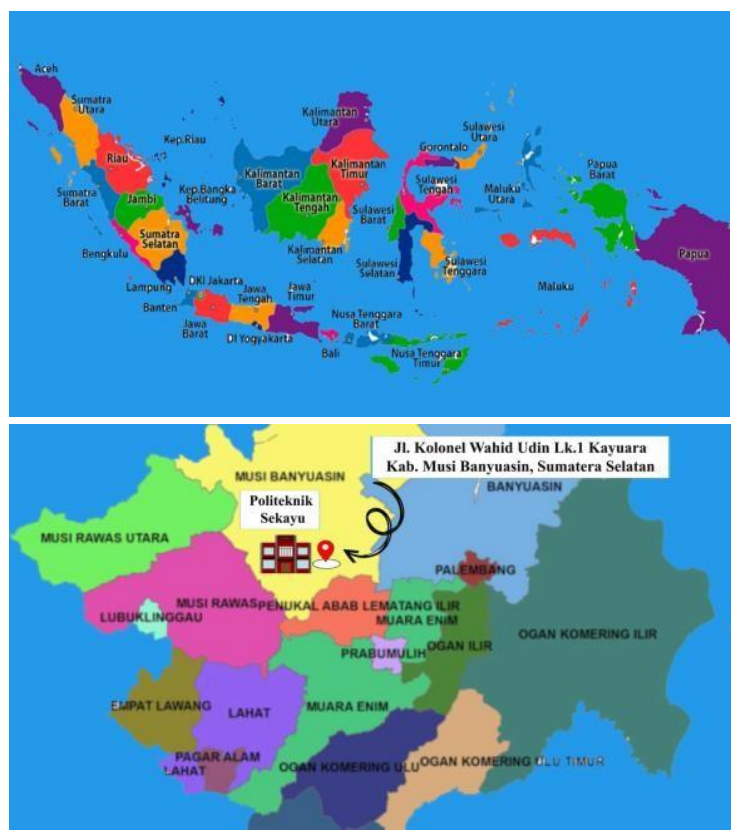

Pada tampilan video ini, menjelaskantentang lokasi politeknik. Peta di buat dengan tiga dimensi agar memberikan efek nyata pada peta. Kemudian membuat null object lalu atur position pada transform. Untuk memberikan efek 3 dimensi, atur pada orientation kemudian sesuaikan dengan Time Graph, untuk memberikan efek smoth animation maka blok Time Graph lalu berikan efekeasy ease yang terdapat pada Keyframe Assisttant.

\subsection{Tampilan Animasi Pendaftaran}

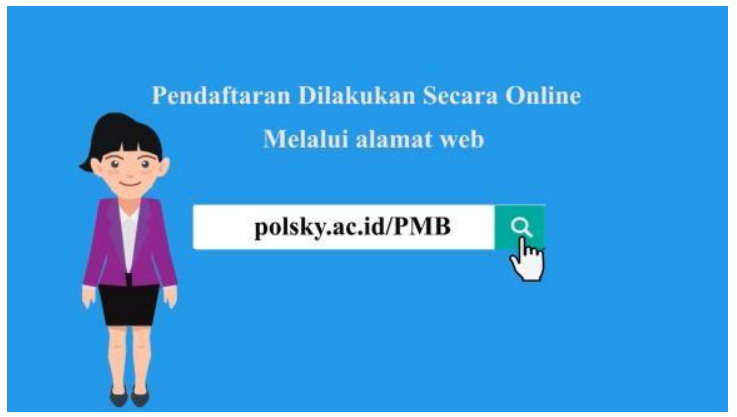

Pada bagian video ini menampilkan cara mendaftar secara online. Dengan adanya gambardan suara yang diberikan pada backsound agar memberikan kejelasan informasi yang disampaikan.

4.3. Tampilan Animasi Lokasi Politeknik 


\begin{tabular}{l|l|lr} 
J & $\mathbf{N}$ & $\begin{array}{l}\text { JURNAL } \\
\text { NASIONAL }\end{array}$ & Jurnal Nasional Ilmu Komputer \\
ILMU & e-ISSN: 2746-1343 \\
KOMPUTER & $\mathrm{K}$ & Vol. 2, No. 3, Agustus 2021 \\
\hline
\end{tabular}
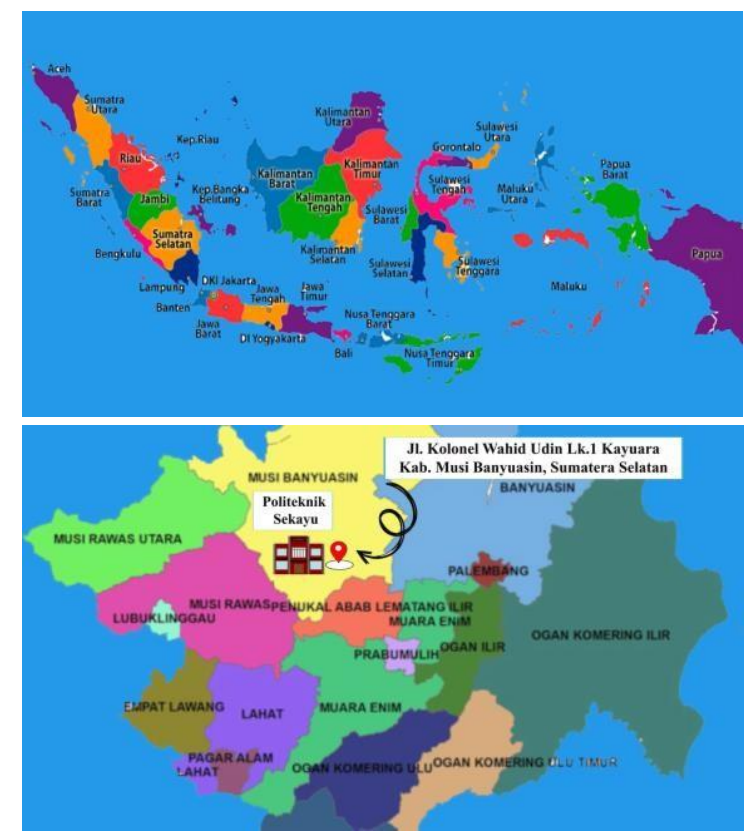

Pada tampilan video ini, menjelaskantentang lokasi politeknik. Peta di buat dengan tiga dimensi agar memberikan efek nyata pada peta . Kemudian membuat null object lalu atur position pada transform. Untuk memberikan efek 3 dimensi, atur pada orientation kemudian sesuaikan dengan Time Graph, untuk memberikan efek smoth animation maka blok Time Graph lalu berikan efekeasy ease yang terdapat pada Keyframe Assisttant.

4.4. Tampilan Animasi Pendaftaran

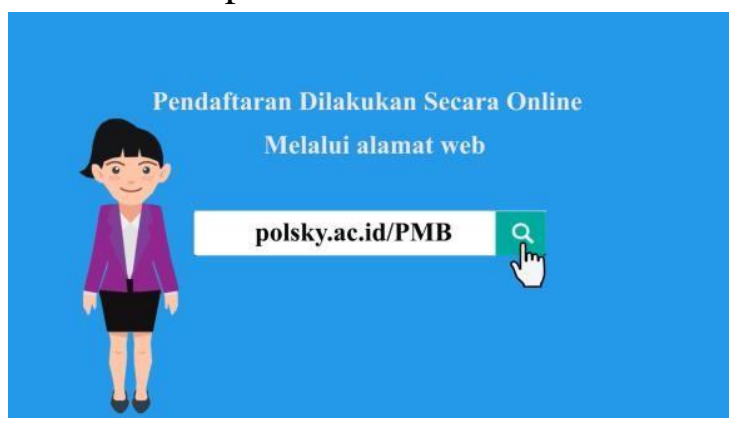

Pada bagian video ini menampilkan cara mendaftar secara online. Dengan adanya gambardan suara yang diberikan pada backsound agar memberikan kejelasan informasi yang disampaikan.

4.5. Tampilan Animasi PembayaranPendaftaran

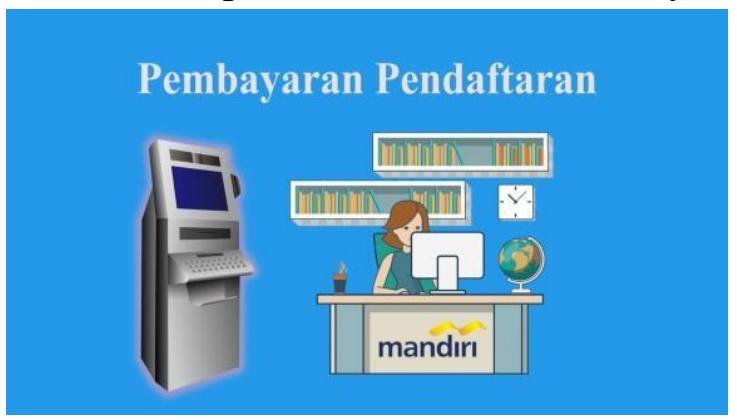

Pada bagian video ini menampilkan cara pembayaran pendaftaran yang dapat dilakukan pada Bank Mandiri dan dapat juga di lakukan melalui Aplikasi Mobile 
Banking.

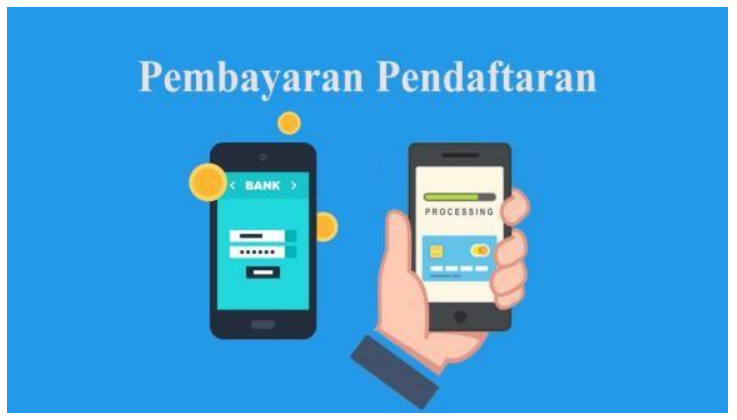

Pada video bagian ini menampilkan No.rekening dan bukti bayar yang harus disimpan untuk bukti pembayaran.

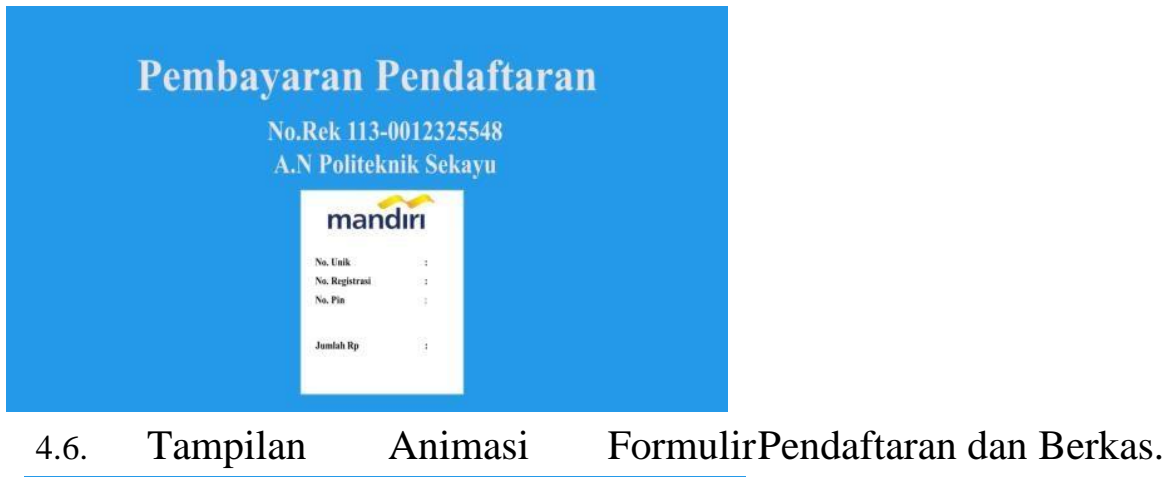

\section{Formulir Pendaftaran}

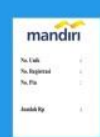

Bukti setor tunai

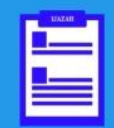

Ijazah / Surat Lulus

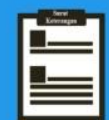

Surat Keterangan

Surat Keteras

Pada video bagian ini menampilkan dokumen yang perlu untuk diupload pada saat mengisi formulir pendaftaran.

4.8. Tampilan Animasi Jurusan yang ada diPoliteknik

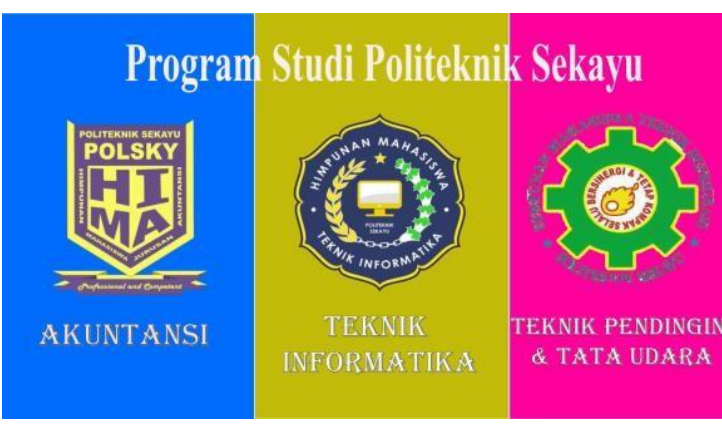

Pada tampilan video ini, menjelaskantentang informasi jurusan yang ada di politeknik. Kemudian membuat null object lalu atur position pada transform. Untuk menyatukan gambar dan tulisan lalu memunculkan gambar dari atas ke bawah. 
4.9. Tampilan Animasi Jadwal Pendaftaran

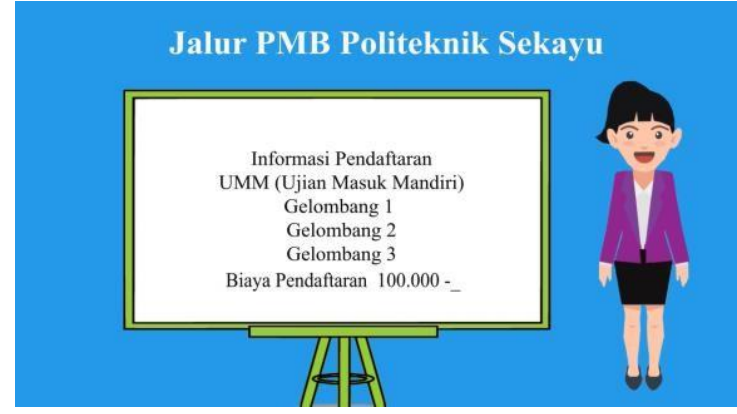

Pada vidio bagian ini menampilkan informasi jadwal pendaftaran penerimaan mahasiswa baru politeknik sekayu dan biaya pendaftaran.

4.10. Tampilan Animasi Informasi LebihLanjut

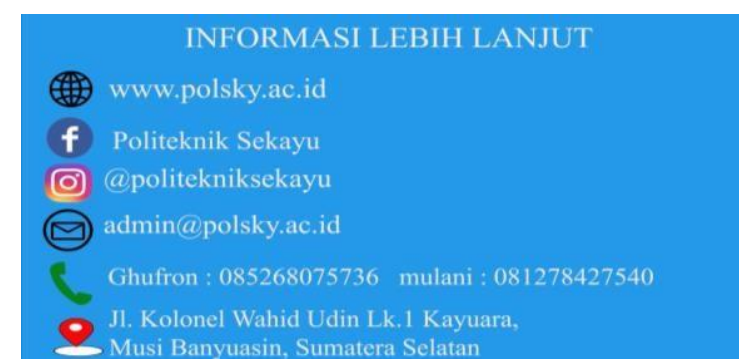

Pada bagian video ini menampilkan social mediayang ada di politeknik.

4.11. Tampilan Animasi Informasi MasaPandemi

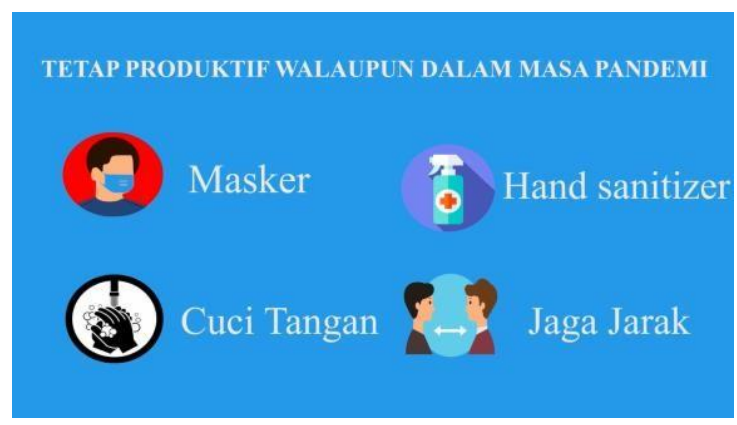

\subsection{Tampilan Animasi Penutup}

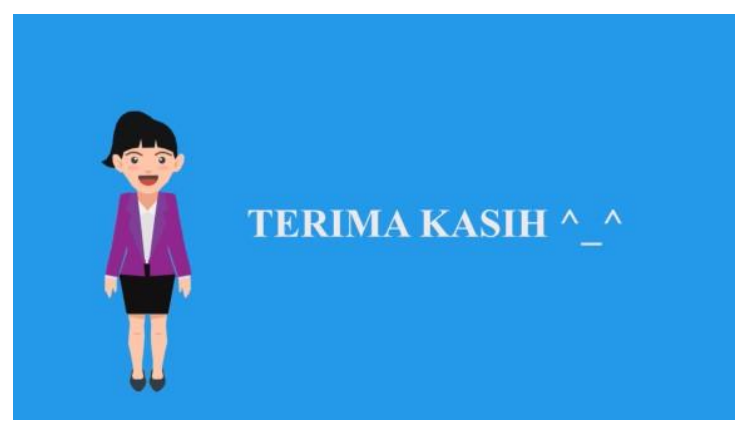

\section{Kesimpulan}

Berdasarkan hasil analisis dan perancangan yang telah dikemukakan pada bab 
sebelumnya, maka Alur Pendaftaran Calon Mahasiswa Baru Politeknik Sekayu Berbasis Multimedia dapat diambil kesimpulan sebagai berikut :

1) Alur Pendaftaran Calon Mahasiswa BaruPoliteknik Sekayu Berbasis Multimedia ini dibuat sebagai media informasi dan promosi Politeknik Sekayu.

2) Hasil Akhir aplikasi ini yaitu berupa Video Profil sebagai media promosi Politeknik bagi calon mahasiswa/i yang berada di berbagai kota dan pedesaan khususnya wilayah SekayuKabupaten Musi Banyuasin.

\section{Referensi}

Antoni, D., \& Akbar, M. (2019). E-supply chain management value concept for the palm oil industry. Jurnal Sistem Informasi, 15(2), 15-29.

Antoni, D., Fikari, D., \& Akbar, M. (2018). The readiness of palm oil industry in enterprise resource planning. Telkomnika, 16(6), 2692-2702.

Antoni, D., Herdiansyah, M. I., Akbar, M., \& Sumitro, A. (2021). Pengembangan Infrastruktur Jaringan Untuk Meningkatkan Pelayanan Publik di Kota Palembang. JURNAL MEDIA INFORMATIKA BUDIDARMA, 5(4), 1652-1659.

Antoni, D., Jie, F., \& Abareshi, A. (2020). Critical factors in information technology capability for enhancing firm's environmental performance: case of Indonesian ICT sector. International Journal of Agile Systems and Management, 13(2), 159-181.

Davis, Gordon B. 2013. Kerangka Dasar Sistem Informasi Manajemen. Palembang: Maxikom

Edi, Sudaryatno, 2014. Panduan Praktis - Adobe After Effects Untuk Kreasi Efek Video.

Fauzi, F., Dencik, A. B., \& Asiati, D. I. (2019). Metodologi Penelitian untuk manajemen dan akuntansi. Jakarta: Salemba Empat.

Jawarti, Sri dan Gaseng Kristiando. 2014. Pembuatan Video Profil Akademi Kebidanan Mitra Husada Karanfanyar Berbasis Multimedia. Jurnal Speed Sentra Penelitian Enginering dan Edukasi. Volume 6 No 4: 1-9.

Juhaeri. 2013. Multimedia Interaktif.

M. Brigida Arie, 2013, Pengertian UML, diakses 14 Maret 202015.59 WIB http://informatika.web.id/pengertian -uml.html/.

Maimunah dkk. Pengertian Company Profile ,2012. Dalam jurnal CCIT vol.5 No.3

Moh. Cindi, Alif Momintan, Rizqi SukmaKharisma. 2013. Perancangan Company Profile The Geek Apple Authorised Reseller Yogyakarta Berbasis Multimedia Flash Sebagai Sarana Promosi Dan Informasi. Jurnal Ilmiah DASI. Volume 14 No 4:32-38.

Nurajizah, Siti. 2017.” Implementasi MultimediaDevelopment Life Cycle

Pada Aplikasi Pengenalan Lagu Anak- Anak Berbasis Multimedia”. Jurnal Prosisko.Volume 3. No. 2. ISSN : 2406-7733.

Permana, Jiwa, Aan, Agus. Ni Ketut Kertiasih dan Putu Budhayasa. 2017. Video Profil Sebagai Sarana Promosi Efektif Dalam Menunjang Eksistensi Program Studi Manajemen Informatika. E-ISSN: 2548- 8570. Volume 6 No 2:1-10. 
Tantra, Rudy. 2012. Manajemen Proyek Sistem Informasi. Yogyakarta: Andi.

Wibowo, Eko Hadi, 2015, Flash Book: Tips dan Trik 21 Project Flash, Andi, Yogyakarta.

Widada HR. 2011. Multimedia Interaktif. Yogyakarta: Pustaka Widyatama.

\section{Copyrights}

Copyright for this article is retained by the author(s), with first publication rights granted to the journal.

This is an open-access article distributed under the terms and conditions of the Creative Commons Attribution license (http://creativecommons.org/licenses/by/4.0/) 